\title{
A NUMBER PROBLEM
}

\author{
by N. Y. WILSON
}

$A$ and $B$ study an array of counters, placed in straight lines on a table, in separated groups (e.g. 28, 53, 1, 16). The counters are to be removed under the following conditions :-

Each " player" may take away

(1) one counter from anywhere (e.g. $27,53,1,16)$ or $(28,20,32,1,16)$ etc.

or (2) three counters from anywhere (e.g. 28, 53, 14) or $(27,52,1,15)$ or $(28,25,17,6,2,1,16)$ etc.

or (3) two adjacent counters from one group (e.g. 28, 51, 1, 16) or $(28,53$, $1,8,6)$ etc.

The "position" at the start is to be regarded as $A$ 's position. So $B$ will always make the first "move". Thereafter they move in turn, the object of each being to make the final move and so "win". The interest of the problem lies in the fact that $A$ 's position, whatsoever it may be, is definitely won or lost (as the case may be) from the start. For instance the illustrative position above is a lost one : and $B$ will win if he plays soundly throughout. He has 48 feasible moves, but only 6 sound moves. I shall justify that statement later.

From the early analysis of the problem, five important facts emerge :-

(1) Any symmetric position inevitably wins (e.g. 1,1 or 3,3 or 5, 5, 8, 8 are wins).

(2) Hence any single group inevitably loses (e.g. 8 loses to 3,$3 ; 13$ loses to 6,6 ).

(3) Every odd position loses-for reasons given later.

(4) Every group either fails to form a win with any smaller group or forms a win with at least one smaller group.

(a) If it fails to win with each and every smaller group, it will be termed a basic group or simply $a$ base.

The bases prove to be $1,2,3,4,6,11,13,14,16,31,33,49,69,86$ (fourteen in all). Hence any two different bases necessarily form a lost position.

(b) If it does win with a smaller group, then it will necessarily win with one and only one of the bases. For instance, $1,5,9,15 \ldots$ are groups such that any pair(s) of them form a win. So they are termed equivalents and in particular each of them is the equivalent of the base 1 . Thus $15,5 \equiv 1,1$ and wins, and $1,5,9,15 \equiv 1,1,1,1$ and wins. Similarly $2,8,22,28 \ldots$ are equivalents, each being the equivalent of base 2 . So $2,22 \equiv 2,2$ wins, $8,22 \equiv 2,2$ wins, $2,8,22,28 \equiv 2,2,2,2$ wins. Hence it follows that every group is either a base or the equivalent of a base. Hence also it follows that every position is equivalent to a series of bases. All pairs in this series may be ignored, 
and so we find that any position, however extended, is equivalent to one containing at most the 14 bases.

(5) As stated in 4(a) no two different bases can form a win. However, certain combinations of three different bases do form a win (termed a 3-base win). For example, $1,2,3 ; 6,4,2 ; 11,4,3 \ldots$ are 3 -base wins, and of course the bases can be replaced with any of their equivalents without prejudice to the win. There are 18 such 3 -base wins (9 fundamental and 9 derived). When these are applied to the equivalent position involving at most the 14

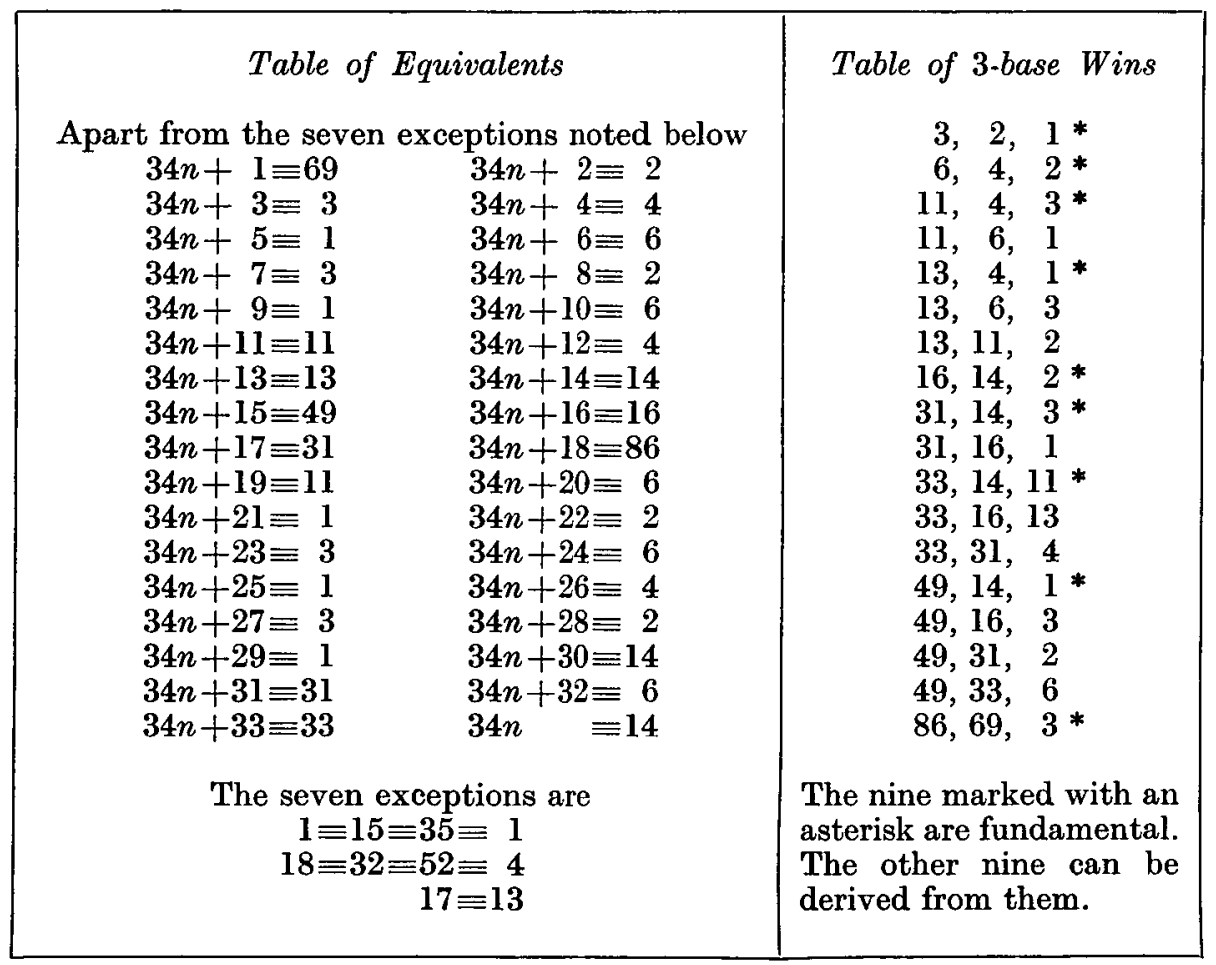

bases (vide last line of 4 above), that position in turn will be found to be equivalent to one containing not more than 3 different bases. The proof of this is very simple, though somewhat lengthy. On it depends the final assessment. If a given position is equivalent to 1 or 2 or 3 different bases, it loses. But if it is equivalent to zero (e.g. 6, 4, 2 or $11,4,3$ ), it wins.

Only extensive and careful analysis will serve to establish the 14 bases and the 18 3-base wins. As each new base is found, the analyst hopes that every greater group will be found to be the equivalent of an established base and will not prove to be another new base. That hope is not realised until the arrival of the base 86. From then onwards every greater group $N$ along with $N+34, N+68, N+102, \ldots$ is found to be the equivalent of $N-34$. Hence it follows that the series of groups comprised in 53 to 86 (both inclusive) 
have exactly the same equivalence as in 87 to 120,121 to 154,155 to 188 , $\ldots$ ad infinitum. Thus $53,87,121,155, \ldots$ each $\equiv 11 ; 54,88,122,156 \ldots$ each $\equiv 6$; $55,89,123,157 \ldots$ each $\equiv 1$; and so on. Rigorous proof of the 34 facts involved

\begin{tabular}{|c|c|c|}
\hline Groups 1 to 52 (the last exception) & \multicolumn{2}{|c|}{$\begin{array}{c}\text { Algebraic law now perfect at } \\
\text { 34-interval }\end{array}$} \\
\hline $\begin{array}{llllllllll}1 & 5 & 9 & 15 & 21 & 25 & 29 & 35 & 39 & 43\end{array}$ & $\begin{array}{lllll}55 & 59 & 63 & 73 & 77\end{array}$ & $\begin{array}{lllll}89 & 93 & 97 & 107 & 111\end{array}$ \\
\hline $22 \quad 28 \quad 36 \quad 42$ & \begin{tabular}{llll|}
56 & 62 & 70 & 76
\end{tabular} & $9096 \quad 104 \quad 110$ \\
\hline $\begin{array}{llll}23 & 27 & 37 & 41\end{array}$ & $\begin{array}{llll}57 & 61 & 71 & 75\end{array}$ & $\begin{array}{llll}91 & 95 & 105 & 109\end{array}$ \\
\hline $\begin{array}{llllllll}4 & 12 & 18 & 26 & 32 & 38 & 46 & 52\end{array}$ & $60 \quad 7280$ & $94 \quad 106 \quad 114$ \\
\hline 6102024 & $\begin{array}{lllll}54 & 58 & 66 & 74 & 78\end{array}$ & $\begin{array}{lllll}88 & 92 & 100 & 108 & 112\end{array}$ \\
\hline 1119 & 79 & 87 \\
\hline 1317 & 81 & 115 \\
\hline 3034 & $\begin{array}{lll}64 & 68 & 82\end{array}$ & $98 \quad 102 \quad 116$ \\
\hline 50 & 84 & 118 \\
\hline 31 & 85 & 119 \\
\hline 33 & 67 & 101 \\
\hline 49 & 83 & 117 \\
\hline & 69 & 103 \\
\hline & 86 & 120 \\
\hline $\begin{array}{l}\text { Heavy type denotes an exception } \\
\text { to algebraic law }\end{array}$ & \begin{tabular}{l}
\multicolumn{1}{c}{$(a)$} \\
Every group $N$ \\
placing as $N+3$ \\
$N+68, \ldots$ are all \\
base
\end{tabular} & $\begin{array}{l}\quad(b) \\
\text { in }(a) \text { has same } \\
\text { in }(b) . N, N+34, \\
\text { equivalents of same }\end{array}$ \\
\hline
\end{tabular}

here requires a great deal of space, as it needs to employ no fewer than $3 \times 18$, i.e. 54 large tables of additions corresponding to the triple elements in the 3-base wins.

I now discuss a point raised previously, namely that every odd position loses. Since all the equivalents of even and odd bases are respectively even and odd (vide following chart) and since every position (however extended) 
is the equivalent of a simple position containing not more than 3 different bases (vide 5 above) it will suffice to list the general groups (not more than three) which are odd. They are (a) $2 n+1$, (b) $2 m+1,2 n,(c) 2 l+1,2 m+1$, $2 n+1$, and $(d) 2 l+1,2 m, 2 n$. The reader will have no difficulty in showing that each of these loses for all values of $l, m, n . \quad B$ turns each of them into a symmetrical pair or two symmetrical pairs or three symmetrical pairs.

Finally, I deal with one example, namely, the position at the commencement of the article. The reader is $B$ who with the assistance of the following charts first ascertains what $A$ 's position amounts to in its lowest equivalent terms and then looks for a sound move.

$A$ 's position is $28,53,1,16 \equiv 2,11,1,16 \equiv 2,6,16(11,61$ wins $.11,1 \equiv 6) \equiv$ $4,16(6,4,2$ wins $\therefore 2,6 \equiv 4)$ which is a combination of two different bases and so loses. Obviously $B$ 's simplest method of procedure is to try to split the 16 group to yield the equivalent of 4 .

So he splits 16 into $13,1 \equiv 4(13,4,1$ wins $\therefore 13,1 \equiv 4)$ or $11,3 \equiv 4(11,4$, 3 wins $\therefore 11,3 \equiv 4)$ or $8,6 \equiv 2,6 \equiv 4(6,4,2$ wins $\therefore 2,6 \equiv 4)$. $B$ can win in other three ways. He can split 28 into 16,10 or 14,12 , or he can split 53 into 30,21 .

I leave the reader to work these out for himself. He will find that each produces zero and so wins. Hence $B$ has exactly 6 ways of choosing two adjacent counters from a single group, so as to leave an even new winning position. His subsequent winning moves will of course depend on $A$ 's various replies.

\section{The Charts and 3-base Wins}

The first chart gives the formulæ for all equivalents of every base, with 7 exceptional groups specially noted. In the second chart the first section shows the actual placings of the first 52 groups with the 7 exceptions in heavy type. Thereafter follow two sections of $\mathbf{3 4}$ groups illustrating the identical placing of corresponding groups.

\section{SPOTTISWOODE ROAD}

EDINBURGh, 9 